\title{
Competitividade de Destinações \\ Turísticas: elementos e indicadores \\ aplicados no estudo da administração \\ turística de Balneário Camboriú - SC, Brasil
}

\author{
Competitiveness in Tourist Destinations: elements and \\ indicators applied to a study of tourism management in \\ Balneário Camboriú - sc, Brazil
}

\author{
Helena Araújo Costa ${ }^{1}$ \\ Valmir Emil Hoffmann ${ }^{2}$
}

\begin{abstract}
RESUMO: O trabalho considera a administração da destinação turística e as relações entre os diversos atores sociais como elementos de competitividade, tendo como objetivo caracterizar a administração do turismo em Balneário Camboriú, aplicando uma adaptação dos indicadores de competitividade do modelo de Dwyer e Kim (2003). É proposta uma triangulação sobre competitividade em empresas, nações e setores, seguida por modelos de competitividade em destinações turísticas. A metodologia consistiu em uma abordagem qualitativa, com coleta de dados primários por meio de entrevistas semi-estruturadas. Os resultados permitem inferir que a administração turística local não apresenta suficiente integração entre os setores para que possa ser apontada como elemento de competitividade.
\end{abstract}

PALAVRAS-CHAVE: administração de destinações turísticas; competitividade; cooperação; Balneário Camboriú, Santa Catarina, Brasil.

ABSTRACT: This paper considers tourism destination management and relationships between different players as competitiveness elements. The study

1. Administradora de Empresas pela Universidade de Brasília - UnB; mestre em Turismo e Hotelaria pela Universidade do Vale do Itajaí - UNIVALI; doutoranda em Desenvolvimento Sustentável - Centro de Desenvolvimento Sustentável na UnB. Professora do Centro de Excelência em Turismo da UnB -CET/UnB. Contato: SQSW 102, bloco B/503 - Sudoeste-70670-202 - Brasília-DF; e-mail: helenacosta@unb.br.

2. Doutor em Ciências Empresariais pela Universidad de Zaragoza, Espanha. Professor titular no Programa de Mestrado Acadêmico em Turismo e Hotelaria da Universidade do Vale do Itajaí - UNIVALI. Contato: UNIVALI - Mestrado em Turismo e Hotelaria - $5^{a}$ Avenida, s/n, Bairro dos Municípios -88330-000 - Balneário Camboriú - SC; e-mail: ehoffmann@univali.br. 
aims to describe the tourism destination management of Balneário Camboriú - SC - Brazil, adapting some indicators presented in the model of destination competitiveness designed by Dwyer and Kim (2003). The conceptual framework approached three main guidelines to discuss the competitiveness in tourism destination: firms, nations and industries, followed by competitiveness theoric models. The research methods were qualitative based on data colleted in partially-structured interviews. The results suggested that local administration in the destination doesn't work in an integrated way to be said as an element of competitiveness.

KEYWORDS: tourism destination management; competitiveness; cooperation; Balneário Camboriú, Santa Catarina (State), Brazil.

\section{Introdução}

A competitividade em destinações turísticas é assunto recente para a academia brasileira. Estudos internacionais já foram empreendidos acerca desse novo tema em países como Espanha, Austrália, Nova Zelândia, Estados Unidos e Inglaterra (Hassan, 2000; Mihalic, 2000; Melián-González \& García-Falcon, 2003; Carús Ribalaygua, 2003). O tema ganha mais espaço por causa da crescente saturação da oferta de destinações turísticas no mercado, o que faz a gestão dos destinos turísticos necessitar manter o foco no conceito de competitividade (Hassan, 2000).

No Brasil, o estudo da competitividade de destinações turísticas ganha relevância na medida em que o diagnóstico do turismo explicitado no Plano Nacional do Turismo (2003) aponta a falta de estruturação da cadeia produtiva do setor como causa para sua baixa competitividade (PNT, 2003). Segundo o mesmo documento, a falta de articulação entre elos públicos e privados dessa cadeia também é identificada como ponto fraco do turismo no Brasil e que, possivelmente, afeta sua competitividade (PNT, 2003) no âmbito administrativo de destinação e de cooperação entre as organizações como elementos de competitividade (Powell, 1990), (Pyke \& Sengenberger, 1993).

A competitividade de destinação começa a ser entendida como algo além dos fatores naturais e da infra-estrutura convencionalmente trabalhados, incluindo em seus estudos fatores relacionados à competitividade dos negócios turísticos (Enright \& Newton, 2004), bem como as relações entre atores sociais na administração da destinação (Dwyer \& Kim, 2003; Pavlovich, 2003).

A abordagem desse trabalho considera que a competitividade transcenda o comportamento de competição predominantemente adotado na bibliografia tradicional, acerca de recursos estratégicos e vantagens competitivas (Barney, 1986, 1991; Porter, 1993, 1999; Baptista, 1997). Uma abordagem mais recente remete à noção de vantagens competitivas compartilhadas ou coletivas, combinando competição e cooperação (Gulati et al., 2000). Entende-se que a competição seja fonte de vantagens competitivas, caso gere inovações e propulsão para mudanças, ao mesmo tempo em que "a simbiose entre empresas locais gera possibilidade de cooperação competitiva” (Urani, 2002 em Cocco et al., 2002: 14). No estudo do turismo, autores como Selin \& Beason (1991), Tremblay (1998), Laws et al. (2002), Watkins \& Bell (2002) e Leiper (2003) vêm desenvolvendo pesquisas sobre relacionamentos interorganizacionais, que já demonstram preocupações com esses conceitos.

Este artigo tem como objetivo geral caracterizar a administração do turismo em Balneário Camboriú, aplicando uma adaptação dos indicadores de competitividade de Dwyer e Kim (2003). Tendo em vista essa finalidade, tem seu referencial teórico em duas partes. A primeira discute a triangulação de competitividade de empresas, países e setores para fornecer base teórica sólida para a reflexão sobre o tema. A segunda, por sua vez, descreve modelos de competitividade de destinações turísticas, discutindo-os com o conteúdo da primeira parte, além de concentrar atenção no modelo empregado no levantamento de dados. Em seguida, são apresentados os aspectos metodológicos, os resultados e as considerações finais, com as limitações esclarecidas e sugestões de estudos posteriores propostas.

\section{Triangulação da competitividade: empresas, países e setores}

O tema da competitividade é amplo e comporta estudos tanto macroeconômicos quanto microeconômicos (Contador, 1996). No referencial teórico que segue, será realizada a triangulação entre noções sobre competitividade de empresas, países e setores com respectivos enfoques em Teoria de Recursos, em concepções de Porter $(1993$; 1999) e na Teoria de Esser (1994). Essa amplitude de discussão parece um caminho interessante para o turismo visto que, para a compreensão de sua gestão, é necessário discutir a visão micro da empresa, o conjunto formado por elas em setores e também as destinações turísticas, intrincadas aglomerações de empresas e setores em dado espaço geograficamente delimitado. As empresas e os países serão abordados primeiramente, já que a noção de competitividade é tratada com maior freqüência em trabalhos dessas áreas, como: Barney $(1986,1991)$; Coyne (1986); Porter (1993, 1999); Black e Boal (1994) e Contador (1996).

Em estudos de competitividade de empresas, a abordagem de recursos é um dos enfoques mais correntes. Recursos são definidos por Wernerfelt (1984) como as forças e fraquezas de dada empresa. A abordagem dos recursos teve início ao colocar em xeque a idéia da vantagem competitiva externa à organização, suscitando que a competitividade estaria mais relacionada aos próprios recursos da empresa do que ao posicionamento de mercado (Molina-Morales \& Hoffmann, 2003). 
Barney (1991) assinala que há uma vantagem competitiva quando a empresa está implementando uma estratégia de criação de valor única, ou seja, que nenhum competidor esteja implementando ao mesmo tempo. Ainda segundo Barney (1991) essa vantagem será competitiva a longo prazo, ou sustentável, se os recursos detiverem quatro características centrais: valor, raridade, dificuldade de imitação e de substituição. Dessa forma, a empresa não seria abordada do ponto de vista de seus produtos, mas sim de seus recursos tangíveis e intangíveis (Wernerfelt, 1984; Collis, 1991). Tradicionalmente, os recursos eram vistos de maneira restrita, apenas como mão-de-obra, capital e terras. Entretanto, com o trabalho de Penrose (1959), iniciouse uma visão mais abrangente sobre eles (Wernerfelt, 1984), originando trabalhos que analisam a contribuição de outros fatores para a vantagem competitiva (Barney, 1986; Slack, 1993), até emergirem as relações entre parceiros como vantagem competitiva em trabalhos mais recentes como o de Lipparini et al. (2000).

Porter (1993) desenvolveu uma teoria sobre a competitividade de países e outras áreas geográficas, concentrando-se em políticas macroeconômicas e em vantagens comparativas como recursos naturais, mão-de-obra e capital. Em obra posterior, o autor incrementa sua visão com o argumento de que a competitividade das localidades está fundamentada nos recursos, no ambiente de negócios proporcionado às empresas, na natureza da demanda e que a prosperidade está relacionada à capacidade da nação de utilizar insumos na produção de bens e serviços valiosos (Porter, 1999). Porter (1999: 171) considera produtividade [grifo no original] o único conceito significativo de competitividade e, em geral, aborda a competição como a relação predominante entre as empresas e os setores.

Considerando a necessidade de ampliação do conceito de competitividade, requisitada pelas mudanças ambientais, parece adequado discutir a competitividade sistêmica de Esser (1994). Essa concepção baseia-se na tomada de decisões conjunta e interação entre agentes de diversos níveis da economia, segundo a interpretação de Orssatto e Hoffmann (1998). A maneira que esses níveis (meta, macro, meso e micro) estão relacionados determina a competitividade do setor ou das empresas do setor (Lanzer et al., 1997). As ponderações de Orssatto e Hoffmann (1998) sobre esse modelo sugerem que sejam levados em consideração, entre outros fatores de competitividade, as inter-relações entre os atores sociais, demonstrando alinhamento à visão de Castells (1999) sobre a nova estrutura mais flexível de uma sociedade que se organiza em redes.

\section{Competitividade de destinações turísticas}

Para o estudo do turismo, cada uma das três abordagens revisadas na seção anterior parece contribuir em certo sentido, porém todas apresentam limitações e nenhuma oferece referencial plenamente satisfatório quando se trata de competitividade de destinações turísticas. Isso se deve ao fato de as destinações turísticas serem intrincados e complexos conjuntos de relações entre diferentes atores sociais aglomerados geograficamente.

A teoria dos recursos pode ser empregada no estudo dos recursos naturais, culturais, construídos e de apoio para o funcionamento do turismo em dada localidade, considerados como vantagens comparativas e não competitivas (Baptista, 1997). Entretanto, não apresenta preocupações com fatores externos à localidade, o posicionamento, a relação com as demais destinações, a administração local ou a interação intersetorial. Essa visão é tradicionalmente aceita, segundo Enright e Newton (2004), e se limita a considerar atributos visíveis, já que a imagem e a atratividade da localidade são compostas por eles.

Já as idéias de Porter (1993; 1999) foram empregadas em diversos estudos privados e governamentais sobre competitividade em destinações turísticas, bem como aconselhadas por autores do turismo como forma interessante de se estudar o assunto (Beni, 2003). O Diamante de Porter aparentemente conjuga elementos de análise pertinentes em uma visão macroeconômica e de posicionamento que pode ser aplicada ao setor turístico sem dar conta de toda a sua complexidade. As limitações podem ser apontadas por trabalhar vantagens comparativas e não competitivas, apresentar apenas relações de competição entre empresas e desconsideradas relações de cooperação, além do foco ser mantido na produtividade como o eixo central da competitividade, ignorando as dimensões de sustentabilidade. $\mathrm{Na}$ sociedade em redes, a competitividade está ligada à velocidade de processamento de informações e à inovação e não aos recursos mais tradicionais, conforme defendido por Porter (Castells, 1999).

A Teoria de Esser (1994), ao levar em consideração relações entre diferentes esferas e atores sociais para a competitividade, parece apontar um caminho mais apropriado para o estudo do turismo e mais alinhado aos pressupostos levantados neste trabalho. Todavia, compreender a competitividade de uma destinação turística parece suscitar um modelo que integre as diversas contribuições das diferentes abordagens.

Há atualmente quadros teóricos alternativos que listam entre os impulsionadores da competitividade a cooperação e a competição interfirmas, as aglomerações locais, as instituições, estruturas sociais e compromissos comuns, entre outros fatores (Enright \& Newton, 2004). Pode-se perceber que esse novo marco teórico dá abertura para que se pense em relações interorganizacionais e cooperação como elementos ou inputs da competitividade no turismo. Sugere-se que o conceito de competitividade seja composto por diversos indicadores atrelados à idéia de que a cooperação entre atores sociais pode ser um elemento de geração de vantagem 
competitiva sustentável com o potencial de resultar no incremento de competitividade da destinação turística (Crouch \& Ritchie, 1999; Ritchie \& Crouch, 2000; Dwyer \& Kim, 2003; Pavlovich, 2003), reforçando a compreensão das relações de reciprocidade e ações integradas como fatores de competitividade advindas de gestão privada e pública como aqueles de Jarillo (1998) e Andion (2003).

Pavlovich (2003) lembra que as relações entre as empresas são um importante componente da vantagem competitiva, especialmente no turismo, agrupando organizações e formando um contexto de destinações. A importância da administração que concilia forças parece destacar-se quando o estudo enfoca o turismo por ser uma atividade inerentemente multissetorial (Beni, 2003). Dias (2003), apesar de não conceituar competitividade, aponta-a como motivo justificável para a cooperação entre os setores público e privado, visto que tanto ela quanto a satisfação do turista dependem da interação dos elementos que compõem a experiência turística.

Podem ser encontrados na literatura de turismo modelos de competitividade para destinações turísticas que seguem diferentes concepções. Há alguns baseados em recursos (Melián-González \& García-Falcon, 2003), e outros voltados prioritariamente para o mercado e o meio ambiente natural (Hassan, 2000; Mihalic, 2000; Carús Ribalaygua, 2003), apenas para citar alguns. Esses modelos foram considerados limitados diante dos pressupostos do trabalho por não tomarem relações entre os setores e a administração da destinação como fatores de competitividade, seguindo a abordagem de raciocínio de Crouch e Ritchie (1999), Ritchie e Crouch (2000) e Dwyer e Kim (2003).

Um primeiro salto qualitativo rumo à construção de um modelo mais abrangente de competitividade de destinações turísticas é dado por Crouch e Ritchie (1999) ao proporem quatro componentes - recursos centrais e atrativos, fatores de apoio, administração da destinaçãó e condições situacionais. O segundo salto dos autores aconteceu na revisão de seu modelo (Ritchie \& Crouch, 2000), quando foram acrescentadas dimensões políticas e de planejamento, além de destacar o papel da sustentabilidade mais completamente. Apesar de esse modelo parecer conveniente, ele é limitado para aplicação empírica pela falta de indicadores. Assim, as propostas desses autores serviram de base para as concepções de Dwyer e Kim (2003), que avançaram na criação de indicadores, porém persiste a limitação quanto à ausência de indicações de como mensurá-los.

O modelo de Dwyer e Kim (2003) pretende possibilitar comparações entre países e entre setores do turismo, oferecendo fusão dos principais elementos destacados na literatura geral sobre competitividade com as características peculiares das destinações turísticas. Esse modelo reconhece a competitividade como objetivo intermediário para o alcance do fim maior, que consiste na prosperidade regional e nacional. Associado ao modelo, há um conjunto de indicadores que os autoressu- põem ser adequado para medir a competitividade de qualquer destinação. O modelo é sistêmico e apresenta diferentes elementos interligados e responsáveis por alguma dimensão da competitividade da destinação, conforme representado na Figura 1.

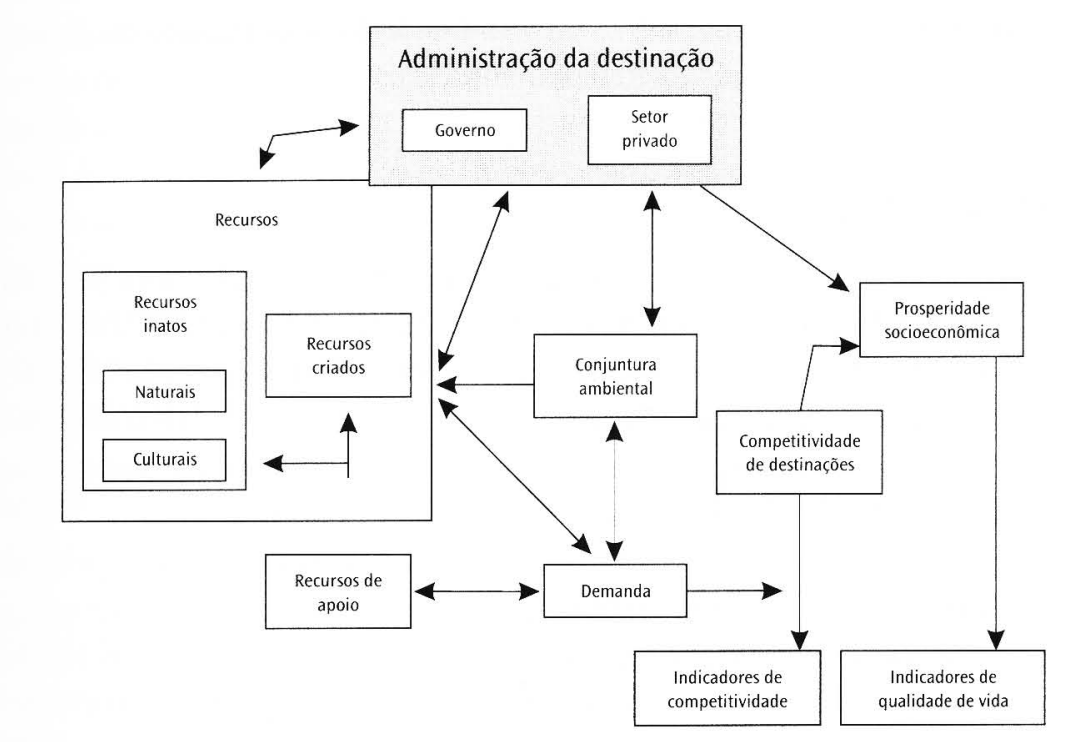

Fonte: Baseado em Dwyer e Kim (2003: 378).

Figura 1. Os principais elementos da competitividade de destinações

Mesmo que sem intenção aparente, podem ser identificados no modelo elementos das abordagens discutidas na seção anterior. $O$ item no qual são apresentados os diversos tipos de recursos em uma destinação turística remete às noções da Abordagem de Recursos já discutida. Das idéias de Porter (1993; 1999), aproximam-se os elementos referentes à conjuntura ambiental do setor e à demanda agregada. Por fim, do modelo apresentado por Esser (1994), aproxima-se o elemento de administração da destinação, que prevê participação e integração entre diferentes setores e esferas em busca da competitividade. ${ }^{3}$

A administração da destinação, conjunto examinado nessa pesquisa, é responsável por destacar os recursos essenciais, reforçar a qualidade e efetividade dos

3. Considerando o foco do trabalho, será exposto no artigo apenas o subsistema da Administração da destinação. Para o modelo completo, consultar a fonte. 
recursos de apoio e melhorar a adaptação à conjuntura ambiental, segundo Crouch e Ritchie (1999). Aqui cinco tipos de atividades de administração têm influência especial na competitividade das destinações: gestão de marketing da destinação, planejamento e desenvolvimento da destinação, organização da administração, desenvolvimento de recursos humanos e gestão do meio ambiente (Dwyer \& Kim, 2003), cada qual com atividades sob responsabilidade do setor público ou do setor privado e, ainda, responsabilidades compartilhadas.

\section{Metodologia da pesquisa}

O trabalho consistiu em um estudo exploratório, visando uma primeira aproximação à realidade da administração da destinação de Balneário Camboriú e das relações que se dão entre os principais atores sociais. O município de Balneário Camboriú pode ser considerado representativo em termos de turismo no estado de Santa Catarina, por ser o principal pólo receptor do estado e um dos maiores do país (Araújo, 2002), justificando a relevância de estudá-lo.

O trabalho de coleta de dados foi realizado em duas etapas, sendo a primeira exploratória (documental-bibliográfica) e, a segunda, o levantamento de campo com organizações turísticas locais representativas dos três setores (público, privado e terceiro setor). Com base no referencial teórico estudado, foi desenvolvido o roteiro para coleta de dados para realizar entrevistas semi-estruturadas. Tendo em vista seu caráter exploratório, mostrou-se mais interessante a opção pela mescla de questões com respostas fechadas combinadas com outras abertas (Laville \& Dionne, 1999). O roteiro era composto por todos os indicadores de administração de destinação propostos pelo modelo de Dwyer e Kim (2003). A opção pelo modelo para respaldar o trabalho foi feita tendo em conta este ser um dos modelos mais completos encontrados na literatura, abordando explicitamente a noção ampliada de competitividade, perpassando a prosperidade socioeconômica da região e o incremento na qualidade de vida de seus residentes, além de possibilitar a inferência da administração da destinação e das relações entre os atores sociais como fatores de competitividade. Cada indicador foi reescrito para apresentar-se como afirmativa que deveria ser classificada pelo entrevistado de acordo com sua opinião em uma escala de concordância de Lickert - por ser essa a escala mais utilizada nos estudos em turismo e adequada na medida em que se deseja medir a atitude do entrevistado diante das afirmações propostas (Shlüter, 2003). A escala aplicada continha cinco pontos, mantendo o ponto central, apesar das discordâncias da academia sobre esse assunto. Essa opção parecia adequada perante a natureza da investigação, ao passo que a neutralidade de percepção poderia ser um aspecto interessante de ser apreendido na investigação.
As entrevistas individuais foram realizadas na primeira semana de junho de 2004 pelo mesmo entrevistador, para manter o máximo de uniformidade. As instituições respondentes foram delimitadas pelo que Malhotra (2001) chama amostragem não probabilística por conveniência, para a qual foram adotados os parâmetros segundo os pesquisadores: a importância das atividades de cada organização para o turismo local, a exclusividade das atividades e/ou atribuições da organização e o número de empresas ou instituições representadas pelas organizações entrevistadas, visando apurar uma visão o mais compartilhada possível. As organizações respondentes foram: o órgão público de turismo local, a maior associação das empresas relacionadas a turismo da cidade e a organização não-governamental voltada para promover o turismo da cidade e atrair eventos. Cada instituição foi representada por um entrevistado que desempenhasse funções de gestão das organizações pesquisadas, conforme sugerido por Enrigth e Newton (2004), e os participantes têm preservados seus nomes e características que os identifiquem.

Quadro 1. Adaptação dos indicadores de administração da destinação de Dwyer e Kim (2003)

\begin{tabular}{|l|l|}
\hline \multicolumn{1}{|c|}{ Variáveis } & \multicolumn{1}{c|}{ Indicadores } \\
\hline $\begin{array}{l}\text { Organização da adminis- } \\
\text { tração } \\
\text { (Atribuições do governo) }\end{array}$ & $\begin{array}{l}\text { Coordenador de setores } \\
\text { Representante da visão dos setores } \\
\text { Elo de comunicação com os demais setores } \\
\text { Fornecedor de informações estatísticas } \\
\text { Executor do monitoramento estratégico e avaliação } \\
\text { do desenvolvimento turístico }\end{array}$ \\
\hline $\begin{array}{l}\text { Políticas, planejamento e } \\
\text { desenvolvimento da } \\
\text { destinação } \\
\text { (Interação intersetorial) }\end{array}$ & $\begin{array}{l}\text { Visão de longo prazo } \\
\text { Visão de futuro em conformidade com valores dos } \\
\text { residentes e dos envolvidos no turismo } \\
\text { Alinhamento com a visão formal da destinação } \\
\text { Desenvolvimento integrado } \\
\text { Adequação às necessidades dos visitantes } \\
\text { Integração às pesquisas } \\
\text { Inventário de atrações } \\
\text { Identificação dos competidores } \\
\text { Apoio da comunidade }\end{array}$ \\
\hline $\begin{array}{l}\text { Administração do marketing } \\
\text { da destinação } \\
\text { (Atribuições do Governo) }\end{array}$ & $\begin{array}{l}\text { Reputação do governo } \\
\text { Imagem e posicionamento da destinação } \\
\text { Monitoramento de atividades de marketing } \\
\text { Adequação dos produtos turísticos } \\
\text { Ligações estratégicas } \\
\text { Identificação de públicos-alvo } \\
\text { Conhecimento do marketing da concorrência }\end{array}$ \\
\hline
\end{tabular}




\begin{tabular}{|l|l|}
\hline \multicolumn{1}{|c|}{ Variáveis } & \multicolumn{1}{c|}{ Indicadores } \\
\hline $\begin{array}{l}\text { Desenvolvimento de } \\
\text { Recursos Humanos } \\
\text { (Atribuições dos setores pú- } \\
\text { blico, privado e de terceiro } \\
\text { setor) }\end{array}$ & $\begin{array}{l}\text { Comprometimento com treinamento e educação em } \\
\text { turismo e hotelaria }\end{array}$ \\
\hline $\begin{array}{l}\text { Gequãação do treinamento e educação } \\
\text { Qualidade em turismo e hotelaria }\end{array}$ \\
$\begin{array}{l}\text { (Atribuições dos setores pú- } \\
\text { blico, privado e de terceiro } \\
\text { setor) }\end{array}$ & $\begin{array}{l}\text { Reconhecimento da importância do turismo sustentável } \\
\text { Leis e regulamentações para meio ambiente e patrimônio }\end{array}$ \\
\hline
\end{tabular}

Fonte: Adaptaçōes de Dwyer e Kim (2003: 404-5).

Após coletados os dados, procedeu-se à análise, confrontando a visão que os setores possuíam acerca da administração do turismo de Balneário Camboriú. Os resultados das entrevistas foram organizados em tabelas comparativas. A análise empreendida aqui foi de caráter qualitativo, tratando os números como símbolos de categorias, detendo-se em compreender as atitudes positivas, neutras e negativas quanto ao assunto. A única exceção consiste no Quadro 2, que cumpre caráter ilustrativo da análise agregada de resultados, utilizando medidas estatísticas descritivas como média e desvio-padrão das pontuações atribuídas pelos respondentes. Os resultados da pesquisa de campo serão apresentados a partir das variáveis e indicadores específicos até uma análise agregada dos resultados, seguindo o ordenamento sugerido pelo Quadro 2.

\section{Resultados}

A organização da administração turística de Balneário Camboriú (Tabela 1) foi avaliada pelo setor público bastante positivamente. Entretanto, a avaliação feita pelo papel do governo aos demais setores recebeu conceitos baixos, o que denota percepção negativa e conflitante desses atores acerca do trabalho que o governo municipal desenvolve na cidade. $O$ único indicador bem avaliado nessa variável foi o que concerne a pesquisas e estatísticas sobre o turismo que o governo desenvolve. O setor privado esclareceu a falta de coordenação existente não apenas entre o público e o privado, mas internamente a esses setores também.

Enquanto o governo demonstra acreditar que esteja coordenando os setores do turismo, comunicando-se efetivamente com eles, além de monitorar e representar a visão de todos, o setor privado discorda totalmente dessas afirmativas. O setor público justifica que, em relação à comunicação, sempre procura comunicar-se (e convida) com todos para reuniões, porém há baixa adesão. $\mathrm{O}$ terceiro setor, no geral, demonstrou percepção menos negativa do que o setor privado.
Entretanto, teve a mesma opinião que a iniciativa privada, a discordância total, quando perguntado se o governo local representava efetivamente a visão de todos os envolvidos com o turismo.

Tabela 1. Organização da administração segundo cada setor entrevistado

\begin{tabular}{|l|c|c|c|}
\hline \multicolumn{1}{|c|}{ Organização da administração } & $\begin{array}{c}\text { Setor } \\
\text { público }\end{array}$ & $\begin{array}{c}\text { Setor } \\
\text { privado }\end{array}$ & $\begin{array}{c}\text { Terceiro } \\
\text { setor }\end{array}$ \\
\hline $\begin{array}{l}\text { Órgão Municipal de Turismo coordena setores, organizações } \\
\text { públicas e privadas }\end{array}$ & 4 & 1 & 2 \\
\hline $\begin{array}{l}\text { Órgão Municipal de Turismo efetivamente representa visão de } \\
\text { todos os envolvidos com o turismo }\end{array}$ & 5 & 1 & 1 \\
\hline $\begin{array}{l}\text { Órgão Municipal de Turismo comunica-se efetivamente com o } \\
\text { setor privado sobre políticas em turismo, planejamento } \\
\text { e desenvolvimento }\end{array}$ & 5 & 1 & 2 \\
\hline $\begin{array}{l}\text { Órgão Municipal de Turismo fornece informações estatísticas } \\
\text { para as políticas de turismo, planejamento e desenvolvimento }\end{array}$ & 5 & 4 & 4 \\
\hline $\begin{array}{l}\text { Órgão Municipal de Turismo monitora estrategicamente } \\
\text { e avalia a natureza e o tipo de desenvolvimento turístico }\end{array}$ & 5 & 1 & 4 \\
\hline
\end{tabular}

Quanto às políticas, ao planejamento e ao desenvolvimento da destinação (Tabela 2), três pontos merecem destaque em razão da divergência de opiniões entre o setor público e os demais: conformidade das políticas, do planejamento e do desenvolvimento com a visão formal de futuro da destinação, a adequação do desenvolvimento às necessidades do turista $e$ a integração dos resultados das pesquisas com o efetivo planejamento e desenvolvimento do turismo local.

Todos os entrevistados consideraram que existe uma visão a longo prazo para o desenvolvimento da destinação, mas quando perguntados sobre qual seria essa visão, não apresentaram homogeneidade e esclareceram que não existe uma visão de futuro formalizada ou escrita. Por isso, os resultados gerados pelos indicadores que abordam formalização prescindem de cautela na interpretação.

Houve unanimidade ao se tratar do inventário turístico e da identificação de atrativos e concorrentes, ainda que a aplicação dessas pesquisas ao efetivo desenvolvimento turístico da cidade tenha sido um ponto conflitante. Foi percebido contraste de opiniões sobre a adequação do desenvolvimento do turismo aos visitantes. Nesse indicador, o setor privado enfatizou que realmente não existe adequação às necessidades do turista e o terceiro setor compartilhou da mesma opinião. Já o governo percebe que o turismo esteja sendo totalmente desenvolvido por ele, de acordo com as necessidades dos turistas e aponta que a iniciativa privada não se adapta. 
Ao se tratar dos valores dos residentes e dos envolvidos com o turismo, as opiniões dos setores não foram muito diferentes entre si, variando apenas da concordância total no caso do setor público e do terceiro setor à concordância no caso do privado. Apesar das opiniões serem positivas, foi identificado que o governo acredita que os residentes desejam elitização do turismo - fato que já está sendo buscado pelos planos do governo. $\mathrm{O}$ terceiro setor e a iniciativa privada divergem do governo nesta questão, tanto por não entenderem a "elitização" como algo positivo quanto por não acreditarem que os residentes sejam consultados para as decisões. Esses setores acreditam que devem ser oferecidos produtos turísticos para todos os níveis de renda e, principalmente, durante todo o ano para que sejam minimizados os efeitos danosos da sazonalidade para os empreendimentos privados. Nessas apurações já é possível apontar a falta de visão comum e de comunicação entre os setores em Balneário Camboriú.

Tabela 2. Políticas, planejamento e desenvolvimento da destinação, segundo cada setor entrevistado

\begin{tabular}{|l|c|c|c|}
\hline \multicolumn{1}{|c|}{\begin{tabular}{c}
\multicolumn{1}{|c|}{ Políticas, planejamento e } \\
desenvolvimento da destinação
\end{tabular}} & $\begin{array}{c}\text { Setor } \\
\text { público }\end{array}$ & $\begin{array}{c}\text { Setor } \\
\text { privado }\end{array}$ & $\begin{array}{c}\text { Terceiro } \\
\text { setor }\end{array}$ \\
\hline $\begin{array}{l}\text { Existe visão a longo prazo para o desenvolvimento do } \\
\text { setor turístico }\end{array}$ & 5 & 4 & 5 \\
\hline A visão da destinação reflete os valores dos residentes & 5 & 4 & 5 \\
\hline $\begin{array}{l}\text { A visão da destinação reflete os valores dos envolvidos com o } \\
\text { turismo (clientes, fornecedores, comerciantes, governo) }\end{array}$ & 5 & 4 & 4 \\
\hline $\begin{array}{l}\text { Políticas de turismo estão em conformidade com a visão formal } \\
\text { da destinação }\end{array}$ & 5 & 2 & 2 \\
\hline $\begin{array}{l}\text { Planejamento e desenvolvimento do turismo estão } \\
\text { de acordo com a visão formal da destinação }\end{array}$ & 5 & 2 & 2 \\
\hline $\begin{array}{l}\text { Desenvolvimento do setor de turismo é integrado ao } \\
\text { de outros setores }\end{array}$ & 5 & 5 & 4 \\
\hline $\begin{array}{l}\text { 0 atual desenvolvimento do turismo é adequado às } \\
\text { necessidades dos visitantes }\end{array}$ & 5 & 1 & 1 \\
\hline $\begin{array}{l}\text { Os resultados das pesquisas são integrados com o } \\
\text { planejamento e desenvolvimento do turismo }\end{array}$ & 5 & 2 & 1 \\
\hline $\begin{array}{l}\text { Atrações e facilidades oferecidas pela destinação } \\
\text { estão inventariadas }\end{array}$ & 5 & 5 & 5 \\
\hline $\begin{array}{l}\text { Maiores competidores e os produtos oferecidos } \\
\text { estão identificados }\end{array}$ & 5 & 3 & 5 \\
\hline Comunidade apóia eventos especiais & 5 & 5 \\
\hline
\end{tabular}

Sobre a comunidade em geral, enquanto o governo acredita que ela apóie totalmente os eventos especiais, a iniciativa privada afirma que ela não é consultada, por isso preferiu não concordar nem discordar da afirmativa. $O$ terceiro setor, assim como o governo, acredita que a comunidade apóia os eventos, já que afirma consultar as entidades de classe que fazem parte da organização. Por fim, um aspecto que revelou bastante coincidência sobre políticas, planejamento e desenvolvimento foi sobre o desenvolvimento turístico estar sendo feito conjuntamente com outros setores na região. Esse indicador fornece informação pouco precisa, na medida em que existe pouca clareza sobre o que compõe o setor turístico e o que é apenas fornecedor dele.

Em geral, as respostas mais homogêneas entre os setores entrevistados ocorreram nas variáveis relativas ao marketing da destinação (Tabela 3). Elas demonstraram atitudes positivas dos setores em variados quesitos, como: reputação do órgão municipal de turismo, efetivo posicionamento da destinação, força da imagem local, adequação dos pacotes e produtos turísticos aos visitantes, conhecimento dos competidores e ligações estratégicas com outras secretarias de turismo.

Tabela 3. Administração do marketing da destinação de acordo com cada setor entrevistado

\begin{tabular}{|l|c|c|c|}
\hline \multicolumn{1}{|c|}{ Administração do marketing da destinação } & $\begin{array}{c}\text { Setor } \\
\text { público }\end{array}$ & $\begin{array}{c}\text { Setor } \\
\text { privado }\end{array}$ & $\begin{array}{c}\text { Terceiro } \\
\text { setor }\end{array}$ \\
\hline A reputação do Órgão Municipal de Turismo é positiva & 4 & 5 & 5 \\
\hline O posicionamento da destinação é efetivo & 5 & 5 & 5 \\
\hline A imagem da destinação é clara e forte & 5 & 5 & 5 \\
\hline $\begin{array}{l}\text { O monitoramento das atividades de marketing da } \\
\text { destinação é eficiente }\end{array}$ & 3 & 4 & 2 \\
\hline Os pacotes oferecidos para a destinação são adequados & 4 & 3 & 4 \\
\hline $\begin{array}{l}\text { Há ligações entre as organizações públicas de turismo } \\
\text { da destinação e o trade de viagens }\end{array}$ & 4 & 4 & 5 \\
\hline $\begin{array}{l}\text { Há ligações estratégicas do Órgão Municipal de Turismo com } \\
\text { outras secretarias municipais de turismo }\end{array}$ & 5 & 1 & 5 \\
\hline $\begin{array}{l}\text { Os produtos da destinação atendem às preferências } \\
\text { dos visitantes }\end{array}$ & 5 & 5 & 5 \\
\hline Órgão Municipal de Turismo identifica públicos-alvo & 5 & 4 & 5 \\
\hline $\begin{array}{l}\text { O marketing da destinação é baseado no conhecimento } \\
\text { dos produtos competidores }\end{array}$ & 4 & 5 & 5 \\
\hline
\end{tabular}

Atitudes neutras, ou seja, sem concordância nem discordância, surgiram por parte dos setores privado e público no que tange à eficiência do monitoramento de 
marketing da destinação. Nesse quesito, o terceiro setor acredita que há potenciais que não estejam sendo explorados, ao passo que a iniciativa privada acredita que essa atividade seja de competência do governo e não esteja sendo desempenhada apropriadamente. $\mathrm{O}$ governo admite falhas nessas atividades, mas enfatiza que apesar dos problemas ainda é modelo para outros órgãos municipais de turismo. Como comentário, o setor privado registrou que o governo tende a se deter a atividades de divulgação, muitas vezes sem conhecimento das reais demandas do setor que estariam mais ligadas à diminuição da sazonalidade e à construção de uma nova imagem que permita aproveitar turisticamente a estação de inverno, mostrando novamente um estrangulamento na comunicação.

A divergência mais expressiva nas respostas de marketing relacionou-se à ligação estratégica entre o órgão de turismo municipal com empresas do trade de viagens, que, segundo o pressuposto desse trabalho, poderia ser elemento de competitividade da destinação ao estabelecer conexões entre os setores público e privado, podendo facilitar o desenvolvimento da destinação. Em Balneário Camboriú, o governo e o terceiro setor acreditaram que exista essa ligação, ao passo que a iniciativa privada discordou totalmente dessa afirmação.

Quanto aos recursos humanos (Tabela 4), o governo e o terceiro setor adotaram uma postura mais positiva, concordando totalmente ou parcialmente com todas as afirmativas. O setor público se diz totalmente comprometido com a capacitação de pessoal para turismo e hotelaria, enquanto o setor privado discorda totalmente da afirmação de que o governo o faça. O governo justifica sua opinião em função dos treinamentos que oferece e da educação para o turismo, que desenvolvido desde o ensino básico, incluindo o nível operacional de execução do turismo. Entretanto, ao ser perguntado sobre o comprometimento do setor privado para com a capacitação, a resposta do setor público foi mais positiva (5) do que a do próprio setor privado (4).

Tabela 4. Administração do desenvolvimento de Recursos Humanos, segundo cada setor entrevistado

\begin{tabular}{|l|c|c|c|}
\hline \multicolumn{1}{|c|}{ Desenvolvimento de Recursos Humanos } & $\begin{array}{c}\text { Setor } \\
\text { público }\end{array}$ & $\begin{array}{c}\text { Setor } \\
\text { privado }\end{array}$ & $\begin{array}{c}\text { Terceiro } \\
\text { setor }\end{array}$ \\
\hline $\begin{array}{l}\text { Setor público comprometido com o treinamento } \\
\text { e a educação em turismo e hotelaria }\end{array}$ & 5 & 1 & 5 \\
\hline $\begin{array}{l}\text { Setor privado comprometido com o treinamento } \\
\text { e a educação em turismo e hotelaria }\end{array}$ & 5 & 4 & 4 \\
\hline $\begin{array}{l}\text { Treinamento e educação adequados às mudanças } \\
\text { das necessidades dos visitantes }\end{array}$ & 5 & 1 & 5 \\
\hline Há alto grau de qualidade do turismo e da hotelaria & 4 & 5 & 5 \\
\hline
\end{tabular}

Ambos os setores divergiram mais uma vez ao tratar da adequação da capacitação da mão-de-obra diante das mudanças das necessidades dos visitantes. O governo acredita que esteja havendo essa adequação perfeitamente, citando como exemplo os cursos de qualidade do atendimento que oferece para policiais, garçons, hoteleiros e outros interessados. Já a iniciativa privada remete essa falta de adequação à universidade, argumentando que ela não prepara os estudantes com as habilidades que o mercado necessita, levantando outro aspecto não relacionado ao poder público.

No tocante à gestão ambiental (Tabela 5), o governo reconhece a si mesmo como totalmente comprometido com a causa, acusando a iniciativa privada de não ter conhecimento a esse respeito. Por outro lado, a iniciativa privada registrou que é totalmente comprometida com o desenvolvimento sustentável do turismo, enquanto discorda do comprometimento governamental.

Tabela 5. Gestão ambiental em Balneário Camboriú segundo os setores entrevistados

\begin{tabular}{|l|c|c|c|}
\hline \multicolumn{1}{|c|}{ Gestão ambiental } & $\begin{array}{c}\text { Setor } \\
\text { público }\end{array}$ & $\begin{array}{c}\text { Setor } \\
\text { privado }\end{array}$ & $\begin{array}{c}\text { Terceiro } \\
\text { setor }\end{array}$ \\
\hline $\begin{array}{l}\text { Setor público reconhece a importância de desenvolver } \\
\text { um turismo sustentável }\end{array}$ & 5 & 2 & 5 \\
\hline $\begin{array}{l}\text { Setor privado reconhece a importância de desenvolver } \\
\text { um turismo sustentável }\end{array}$ & 1 & 5 & 5 \\
\hline $\begin{array}{l}\text { Existem leis e regulamentação protegendo o ambiente } \\
\text { e o patrimônio }\end{array}$ & 5 & 5 & 5 \\
\hline $\begin{array}{l}\text { Há pesquisas e monitoramento dos impactos ambientais } \\
\text { do turismo }\end{array}$ & 5 & - & 5 \\
\hline
\end{tabular}

Relativo ao monitoramento dos impactos ambientais, o órgão municipal de turismo concorda totalmente que seja realizado, entretanto registra que não faz parte de suas atribuições. Já o setor privado afirma que a atividade turística privada (bares, hotéis, restaurantes e similares) não causa muitos impactos ambientais em face da urbanização que já existe, atribuindo a responsabilidade às construtoras e empreiteiras, e preferiu não emitir opinião sobre a realização de pesquisas e monitoramento de impactos ambientais, por entender que essa não seja uma atribuição que caiba ao setor que representa. Mais uma vez, o terceiro setor teve atitude mais positiva, já que sua pontuação foi a mais alta. A percepção do terceiro setor é de que tanto o setor privado quanto o público estão comprometidos com o desenvolvimento sustentável do turismo em todos os quesitos perguntados. 
Traçando uma análise mais global dos resultados, observou-se que o setor público é aquele que apresenta uma avaliação mais positiva no que tange à administração turística da cidade, tomando as pontuações agregadas de todos os itens do roteiro de entrevista (Quadro 2). ${ }^{4}$ Percebeu-se uma compreensão do governo bastante positiva acerca de si mesmo e de seu desempenho em funções de organização, planejamento e desenvolvimento do setor turístico, somando a pontuação total mais elevada, obtendo 158 pontos de um total possível de 170. Enquanto isso, o setor privado atribuiu a mais baixa pontuação (108 pontos) entre as organizações entrevistadas, e o terceiro setor ficou em uma posição intermediária (123 pontos). Isso pode ser resultado da composição dos indicadores do modelo empregado, que aborda muitos itens que poderiam ser considerados como atribuições do governo, levando a uma auto-avaliação possivelmente tendenciosa por essa parte.

A média das pontuações totais consistiu em 129,67 pontos, o que mostra o setor público como o único com desvio-padrão positivo $(28,33)$, enquanto os demais tiveram pontuações abaixo da média. Isso dá indicativos quantitativos de que a postura do setor público seja a mais positiva quanto aos assuntos investigados.

Quadro 2. Pontuações totais por setor entrevistado perante o valor máximo de referência, média e desvio-padrão

\begin{tabular}{|l|c|c|c|}
\hline & $\begin{array}{c}\text { Setor } \\
\text { público }\end{array}$ & $\begin{array}{c}\text { Setor } \\
\text { privado }\end{array}$ & $\begin{array}{c}\text { Terceiro } \\
\text { setor }\end{array}$ \\
\hline Pontuação total atribuída pelos entrevistados & 158 & 108 & 123 \\
\hline Valor máximo de referência & 170 & 170 & 170 \\
\hline Média & 129,67 & 129,67 & 129,67 \\
\hline Desvio-padrão & 28,33 & $-21,67$ & $-6,67$ \\
\hline
\end{tabular}

Comparando os desvios das pontuações entre os setores, o maior encontrado é aquele entre o setor privado e o público que, respectivamente, tiveram desvios de 28,33 e $-21,67$. Os contrastes entre as respostas dadas pelos setores público e privado estiveram bastante presentes e merecem destaque. Em $25 \%$ das afirmações totais do levantamento, o governo concordava totalmente, enquanto o setor privado discordava totalmente das afirmativas positivas sobre as atividades desenvolvidas pelo poder público. Percebeu-se menor desvio entre as percepções da iniciativa privada e do terceiro setor, ainda que o setor privado tenha apre-

4. O Quadro 2 apresenta o valor máximo de referência, ou seja, aquela pontuação que resultaria caso todas as questões fossem respondidas com o ponto mais alto da escala. Cabe lembrar que na escala adotada, quanto mais alta a pontuação, mais positiva é a atitude da afirmativa proposta. sentado desvio-padrão negativo e cerca de três vezes e meia mais baixo do que o terceiro setor. Esse maior alinhamento dos pontos de vista da iniciativa privada e do terceiro setor poderia ser explicado pela compreensão do terceiro setor como representante da iniciativa privada que, em muitos casos, busca suprir o papel do governo de coordenador de esforços entre os diferentes segmentos envolvidos no turismo, inclusive buscando ser a ligação entre o setor público e o privado locais, conforme afirmado nas entrevistas.

Apesar de não constar entre os indicadores, todos os setores entrevistados apontaram a falta de recursos como entrave para o desenvolvimento turístico na região e como obstáculo para a administração da destinação. O governo afirma ter orçamento restrito, o privado afirma não ter apoio financeiro público e ter limitações de capital para investir em projetos comuns, normalmente realizados com a contribuição dos afiliados. O terceiro setor indica que os recursos financeiros coletados pela contribuição dos mantenedores são escassos e que os recursos públicos municipais estão atrelados aos interesses partidários, e não se voltam para interesses compartilhados.

\section{Considerações finais}

O objetivo geral deste trabalho consistiu em caracterizar a administração do turismo em Balneário Camboriú aplicando uma adaptação dos indicadores de competitividade de Dwyer e Kim (2003). Considerando o contexto da competitividade sistêmica, faz-se necessário que seja levada em consideração a diversidade de setores envolvidos com o turismo. Isso requer um modelo de competitividade que examine as relações entre esses atores, já que eles são responsáveis pela criação de valor e pela manutenção da vantagem competitiva sobre os demais destinos.

Com a breve triangulação realizada no referencial teórico, fica evidenciado que o conceito de competitividade é controverso e de difícil compreensão, corroborando essa idéia advinda de Castells (1999). A nova dinâmica do ambiente externo traz novos padrões de comportamento estratégico para os estados e para as empresas, tornando limitado o alcance dos trabalhos que não destacam as relações entre organizações, tanto públicas quanto privadas, como fator de competitividade. Isso se dá por causa do ambiente globalizado e, no que tange ao Brasil, desafiado pela necessidade de conciliar todas as forças sociais em um modelo de competitividade que desenvolva a economia do país (Orssatto \& Hoffmann, 1998).

Foi possível apontar que, apesar de seminais, abordagens de competitividade como a Teoria dos Recursos e os trabalhos de Porter aqui examinados mostram-se insuficientes para compreender a necessidade emergente por um novo modelo de competitividade que leve em consideração as interações e articulações entre 
atores sociais para o estudo do turismo. Assim, a Teoria de Esser (1994) parece apresentar concepção mais adequada para o mundo competitivo e globalizado que se configura, e sugere relações entre atores sociais, podendo fornecer contribuições para a pesquisa de competitividade turística. As três abordagens citadas, apesar de agregarem pontos de vista válidos para a compreensão da competitividade de destinações, apresentam-se ainda limitadas quando consideradas isoladamente.

Entre os modelos de competitividade para destinações turísticas apurados, foram apontadas também algumas visões parciais e limitantes do fenômeno, já que a administração da destinação turística e as relações entre os setores que compõem o setor do turismo foram ignoradas por alguns autores. Assim, o modelo de Dwyer e Kim (2003) foi cogitado como o mais próximo da busca de entendimento ampliado sobre a competitividade de destinações turísticas por considerar que o planejamento e as políticas de turismo devem ter visão sistêmica, agregando comerciantes, governo e líderes comunitários ao redor da administração da destinação no que tange às políticas, ao planejamento, ao desenvolvimento, ao marketing, aos recursos humanos e naturais.

A análise dos resultados obtidos com aplicação dos indicadores de competitividade da administração da destinação de Dwyer e Kim (2003) mediante o estabelecimento de uma escala de concordância de cinco pontos permitiu inferir que a administração turística de Balneário Camboriú não apresenta integração ou visões comuns entre os setores público, privado e o terceiro setor em grande parte dos indicadores analisados.

Tratando os dados de maneira agregada, percebeu-se que o setor público foi aquele ator social que teve as opiniões mais positivas, totalizando maior acúmulo de pontos e mais alto desvio-padrão positivo, orientando o aumento do valor da média de pontuações dos três setores conjuntamente. Isso pode ter sido facilitado pela limitação do modelo quando empregado para uma análise comparativa entre os setores, já que grande parte dos indicadores dizem respeito a atividades entendidas como responsabilidade do setor público, gerando um viés na auto-avaliação desse setor. Ainda nessa análise, percebeu-se o setor privado com opiniões mais negativas e mais alinhadas com aquelas fornecidas pela instituição representante do terceiro setor local, que se compreende como um representante da iniciativa privada e com papel de estabelecer o diálogo entre as empresas locais e o órgão de turismo.

Diversas opiniões registradas nas entrevistas permitem inferir poucos traços de contratos relacionais (comportamentos opostos à "queda de braço"), de troca de informações ou de ações coletivas, considerados os pilares da cooperação segundo Knorringa e Meyer-Stamer (1998). Essas lacunas poderiam causar prejuízos em detrimento dos potenciais benefícios da cooperação interorganizacional no turismo para a competitividade.
Confrontando os resultados alcançados com o modelo referencial adotado, fica claro que, para que a administração da destinação fosse considerada elemento agregador de competitividade, seria necessário desenvolver as atividades centrais de organização, planejamento, desenvolvimento, gestão de marketing, recursos humanos e meio ambiente, englobando todos os atores sociais (Dywer \& Kim, 2003 ) e desenvolvendo relações entre eles (Orssatto \& Hoffmann, 1998) ao redor de uma visão comum para o futuro da destinação (Dywer \& Kim, 2003).

Os resultados ficaram limitados em face da impossibilidade de entrevistar todas as pessoas previamente delineadas como representativas, bem como da presença de questões fechadas no roteiro de entrevista. Sugere-se que sejam abordadas outras questões-chave para a compreensão de relações entre os atores sociais da administração da destinação como confiança entre eles, oportunismo e reputação, para entender comportamentos aqui identificados. Para possibilitar uma análise mais profunda, sugerem-se estudos futuros com maior número de entrevistados representativos de cada setor do município, permitindo o avanço das técnicas qualitativas e quantitativas empregadas no tratamento dos dados.

\section{Referências bibliográficas}

ANDION, Carolina. 2003. Análise de redes e desenvolvimento local sustentável. Revista de Administração Pública, vol. 37, n. 5, p. 1033-54, set/out.

ARAÚJO, M. R. 2002. Utilização de praias para atividades recreativo-esportivas: o caso da Praia Central de Balneário Camboriú - SC. Dissertaçāo (Mestrado em Turismo e Hotelaria) - UnIVALI, Balneário Camboriú, SC. BAPTISTA, Mário. 1997. Turismo: competitividade sustentável. Lisboa: São Paulo: Verbo.

BARNEY, Jay. 1986. Organizational culture: can it be a source of competitive advantage? Academy of Management Review, vol. 11, n. 3, p. 656-665.

- 1991. Firm resources and sustained competitive advantage. Journal of Management, v. 17, n. 1, p. $99-120$

BENI, Mário Carlos. 2003. Análise estrutural do turismo. 8.ed. São Paulo: SENAC-SP. p. 98-125.

BLACK, Janice A. \& BOAL Kimberly B. 1994. Strategic resources: traits, configurations and paths to sustainable competitive advantage. Strategic Management Journal, v. 15, p. 131-148.

CARÚS RIBALAYGUA, Luis. 2003. Destino turístico recreativo de alta montaña: modelos actuales de análisis y dirección estratégica. Estudios y Perspectivas en Turismo, vol. 12, p. 243-254.

CASTELIS, Manuel. 1999. A sociedade em rede: a era da informação: economia, sociedade e cultura. São Paulo: Paz e Terra.

COCCO, G., URANI, A. \& GALVÃO, A. (Orgs.). 2002. Empresários e empregos nos novos territórios produtivos. 2.ed. Rio de Janeiro: SEBRAE; DP\&A.

CONTADOR, José Celso. 1996. Modelo para aumentar a competitividade industrial: a transição para a gestão participativa. São Paulo: Edgard Blucher.

CROUCH, Geoffrey I. \& RITCHIE, J. R. Brent. 1999. Tourism, competitiveness and societal prosperity. Journal of Business Research, vol. 44, n. 3, p. 137-152.

DIAS, Reinaldo. 2003. Planejamento do turismo: política e desenvolvimento do turismo no Brasil. São Paulo: Atlas. p. 180-204.

DWYER, Larry \& KIM, Chulwom. 2003. Destination competitiveness: determinants and indicators. Current Issues in Tourism, vol. 6, n. 5, p. 369-390. 
ENRIGHT, Michael J. \& NEWTON, James. 2004. Tourism destination competitiveness: a quantitative approach. Tourism Management, n. 25, p. 777-788.

GULATI, R., NOHRIA, N. \& ZAHEER, A. Strategic networks. 2000. Disponível em: < http://www.ranjaygulati. com/newresearch>. Acesso em: 27 nov. 2004.

HASSAN, Salah S. 2000. Determinants of market competitiveness in an environmentally sustainable tourism industry. Journal of Tourism Research, vol. 38, p. 239-245, feb.

JARILLO, J. Carlos. 1988. On strategic networks. Strategic Management Journal, vol. 9, p. 31-41.

KNORRINGA, Peter \& MEYER-STAMER, Jorg. 1998. New dimensions in local enterprise co-operation and development: from clusters to industrial districts. In: UNCTAD (Org.). New approaches to science and technology co-operation and capacity building. (ATAS Bulletin XI). New York: Geneve: United Nations, November.

LANZER, Edgar, CASAROTTO FILHO, Nelson, CUNHA, Cristiano et al. 1997. Análise da competitividade sistêmica do setor de móveis em Santa Catarina. Florianópolis: BRDE.

LAVILLE, Christian \& DIONNE, Jean. 1999. A construção do saber científico: manual de metodologia da pesquisa em ciências humanas. Porto Alegre: Artes Médicas Sul; Belo Horizonte: Editora UfMG.

LAWS, Eric, SCOTT, Noel \& PARFITT, Nick. 2002. Sinergies in destination image management: a case study and conceptualization. International Journal of Tourism Research, vol. 4, p. 39-55.

LEIPER, Neil. 2003. Tourism management. Australia - NSw: Pearson SprintPrint.

MALHOTRA, Naresh K. 2001. Pesquisa de marketing: uma orientação aplicada. Bookman: Porto Alegre.

MELIÁN-GONZÁLEZ, Arturo \& GARCÍA-FALCON, Juan Manuel. 2003. Competitive potential of tourism in destinations. Annals of Tourism Research, vol. 30, n. 3, p. 720- 740.

MOLINA-MORALES, Francisco J. M. \& HOFFMANN, Valmir E. 2003. Conhecimento como recurso estratégico: uma análise em distritos industriais do Brasil e da Espanha. IBERAMERICAN ACADEMY OF MANAGEMENT, 3. Anais... São Paulo, dez.

ORSSATTO, Carlos Henrique \& HOFFMANN, Valmir Emil. 1998. Em direção a um novo modelo de competitividade em um ambiente globalizado. Revista Alcance, Itajaí, ano v, n. 3, jul./dez, p. 05-13.

PAVLOVICH, Kathryn. 2003. The evolution and transformation of a tourism destination network: the Waitomo Caves, New Zealand. Tourism Management, vol. 24, p. 203-216.

PLANO NACIONAL DE TURISMO - PNT. 2003. Brasília.

PORTER, Michael. 1993. A vantagem competitiva das nações. Rio de Janeiro: Campus.

Campus.

1999. Competição $=$ On competition: estratégias competitivas essenciais. 5.ed. Rio de Janeiro:

PYKE, F. \& SENGENBERGER, W. (Orgs.). 1993. Los distritos industriales y las pequeñas empresas III: distritos industriales y regeneración económica local. Madrid: Ministerio de Trabajo y Seguridad Social.

RITCHIE, J. R. Brent \& CROUCH, Geoffrey I. 2000. The competitive destination: a sustainability perspective. Tourism Management, vol. 21, n. 1, p. 1-7.

SHLÜTER, R. G. 2003. Metodologia da pesquisa em turismo e hotelaria. São Paulo: Aleph. (Série Turismo). SELIN, S. \& BEASON, K. 1991. Interorganizational relations in tourism. Annals of Tourism Research, vol. 18, p. 639-652.

SLACK, N. 1993. Vantagem competitiva em manufatura: atingindo competitividade nas operações industriais. São Paulo: Atlas.

WATKINS, M. \& BELL, B. 2002. The experience of forming business relationships in tourism. International Journal of Tourism Research, n. 4, p. 15-28.

TREMBLAY, Pascal. 1998. The economic organization of tourism. Annals of Tourism Research, vol. 25, n. 4, p. $837-859$.

Recebido em: 18/02/2005.

Aprovado em: 20/02/2006. 